\begin{tabular}{|c|l|}
\hline Title & Conformational property of ethoxybenzene as studied by laser-jet spectroscopy and theoretical calculations \\
\hline Author(s) & Egawa, Toru; Y amamoto, Daisuke; Daigoku, Kota \\
\hline Citation & $\begin{array}{l}\text { Journal of Molecular Structure, 984(1-3), 282-286 } \\
\text { https://doi.org/10.1016/.molstruc.2010.09.042 }\end{array}$ \\
\hline Issue Date & 2010 -12-15 \\
\hline Doc URL & http://hdl.handle.net/2115/44345 \\
\hline Type & article (author version) \\
\hline File Information & egawa.pdf \\
\hline
\end{tabular}

Instructions for use 


\title{
Conformational property of ethoxybenzene as studied by laser-jet spectroscopy and theoretical calculations
}

\author{
Toru Egawa $^{\mathrm{a}, \mathrm{b} *}$, Daisuke Yamamoto ${ }^{\mathrm{b}}$ and Kota Daigoku ${ }^{\mathrm{a}}$ \\ ${ }^{a}$ College of Liberal Arts and Sciences, Kitasato University, Sagamihara 252-0373, Japan \\ ${ }^{\mathrm{b}}$ Division of Chemistry, Graduate School of Science, Hokkaido University, \\ Sapporo 060-0810, Japan
}

(Received 17 July 2010, Received in revised form 27 September 2010, Accepted 27 September 2010)

\begin{abstract}
The conformational property of ethoxybenzene has been investigated by means of the laser-jet spectroscopy and the theoretical calculations. The quantum-mechanical analysis of the two-dimensional potential surfaces for the $\mathrm{S}_{0}$ and $\mathrm{S}_{1}$ states that have been obtained from the DFT and TDDFT calculations, respectively, has been carried out. Its result suggested the existence of the second conformer (gauche) in addition to the main conformer (trans) in the both states, and it was predicted that the $0-0$ band of the gauche conformer would appear at about $400 \mathrm{~cm}^{-1}$ lower than that of the trans conformer. The $\mathrm{S}_{1} \leftarrow \mathrm{S}_{0}$ fluorescence excitation spectrum of jet-cooled ethoxybenzene has been measured. The peak that is assignable to the $0-0$ band of the second conformer has been observed, whose spectral position (red-shifted from that of the trans conformer for about $229 \mathrm{~cm}^{-1}$ ) is qualitatively consistent with the theoretical prediction.
\end{abstract}

Keywords: Ethoxybenzene; Conformation; Fluorescence excitation spectrum; Supersonic free jet; DFT calculations; Time-resolved DFT calculations

* Corresponding author. Phone/Fax: +81-42-778-8088.

E-mail address: egawa@kitasato-u.ac.jp 


\section{Introduction}

The conformational properties of molecule have been one of the central themes of structural chemistry. Diffraction and spectroscopic techniques have long been utilized for identification of the stable conformers of gas phase molecules, and recently quantum chemical calculations are thought to be reliable sources to provide information about the number of stable conformers and their energy differences. However, inconsistent results are sometimes obtained even for the conformational property of relatively simple molecules. For example, there have been studies with slightly different conclusions as for the existence of the second conformer for $\alpha, \alpha, \alpha$-trifluoroanisol $[1,2]$.

Ethoxybenzene, the target of the present study, is another example of molecules with inconsistent reports about the conformational property. A preliminary conformational study of ethoxybenzene by means of gas electron diffraction was first reported in 1993, in which it was concluded that ethoxybenzene exists as a mixture of trans and gauche conformers (see Fig. 1) in the gas phase [3]. However, two reports have come out recently from independent research groups [4,5], with a conclusion contrarily to that of Ref. [3]. Cinacchi and Prampolini have carried out DFT calculations to make a two-dimensional potential map for the $\mathrm{C}_{\text {ring }}-\mathrm{O}$ and $\mathrm{C}_{\text {ethyl }}-\mathrm{O}$ internal rotation of ethoxybenzene (corresponding to the $\phi_{1}$ and $\phi_{2}$ angles, respectively, shown in Fig. 1) in the $\mathrm{S}_{0}$ state [4]. Two unique minima, corresponding to the trans and gauche, seem to exist on their potential surface with the former being more stable. However, they have not mentioned the gauche conformer and the quantum-mechanical energy level calculation by using their potential surface have not been carried out. Ramanathan et al. have measured the fluorescence excitation and dispersed fluorescence spectra of jet-cooled ethoxybenzene [5]. They have concluded the existence of only one conformer (trans) of ethoxybenzene in the gas phase because there was no band assignable to the $0-0$ band of the second conformer in their fluorescence excitation 
spectrum. However, the wavenumber range of their measurement was only in the vicinity of the $0-0$ band of the trans conformer and it does not seem to be wide enough to rule out the possibility of the second conformer.

In the present study, a fluorescence excitation spectrum of jet-cooled ethoxybenzene has been measured with a rather wide wavenumber range. In addition, theoretical calculations have been carried out to obtain two-dimensional potential surfaces not only for the $\mathrm{S}_{0}$ state but also for the $\mathrm{S}_{1}$ state. Quantum-mechanical energy level calculations have also been carried out to predict the peak positions of the excitation spectrum. All the experimental and theoretical data have been combined to draw a final conclusion about the existence of the gauche conformer of ethoxybenzene.

\section{Experimental}

A commercial sample (Tokyo Kasei Kogyo Co., Ltd.) with purity better than $99 \%$ was used without further purification. The $\mathrm{S}_{1} \leftarrow \mathrm{S}_{0}$ fluorescence excitation spectrum was measured by using an apparatus reported previously [6]. The carrier gas used was He and the stagnation pressure was about $2 \mathrm{~atm}$. The temperature of the sample holder was kept at $263 \mathrm{~K}$ in order to obtain the appropriate sample concentration. The nozzle (General Valve 900 series) was not heated but its temperature rose up to $323 \mathrm{~K}$ during the measurement. The orifice diameter of the nozzle was $0.5 \mathrm{~mm}$. The jet-expanded sample was irradiated by the UV laser (Lambda-physik, Compex 110 excimer laser and SCANmate 2UV dye laser equipped with an auto-tracking SHG system) at $30 \mathrm{~mm}$ downstream of the nozzle outlet. The applied laser energy was about $150 \mu \mathrm{J} /$ pulse. The laser and nozzle systems were driven synchronously at the repetition rate of $30 \mathrm{~Hz}$. The fluorescent light was focused on a Hamamatsu R212 PMT, in front of which cut-off filters $(300 \mathrm{~nm})$ were placed. The output signal from the PMT was processed by a pre-amplifier and a boxcar averager (Stanford Research Systems, SR-250). 


\section{Theoretical calculations}

Program Gaussian 09 [7] was used for all the calculations. In order to obtain the potential map for the electronic ground state $\left(\mathrm{S}_{0}\right)$, a series of geometry optimizations were carried out by fixing the internal rotation angles, $\phi_{1}$ and $\phi_{2}$, independently at $0-180^{\circ}$ with an interval of $30^{\circ}$. The method used was B3LYP [8,9] with a cc-pVTZ basis set [10]. For the $\mathrm{S}_{1}$ excited state, the potential map was obtained similarly with the TDDFT method [11-13] and a cc-pVTZ basis set (i.e., TDDFT/B3LYP/cc-pVTZ).

\section{Analyses}

\subsection{Potential surfaces.}

The potential energies obtained for the $\mathrm{S}_{0}$ and $\mathrm{S}_{1}$ states were fitted to the functional form

$$
V\left(\phi_{1}, \phi_{2}\right)=\sum_{m, n=0}^{6} V_{m, n}^{\mathrm{c}} \cos \left(m \phi_{1}\right) \cos \left(n \phi_{2}\right)+\sum_{m, n=1}^{4} V_{m, n}^{\mathrm{s}} \sin \left(m \phi_{1}\right) \sin \left(n \phi_{2}\right)
$$

The resultant potential constants, $V_{m, n}^{\mathrm{c}}$ and $V_{m, n}^{\mathrm{s}}$, are listed in Table 1 and the reproduced potential surfaces are shown in Fig. 2. The potential surface for the $\mathrm{S}_{0}$ state is essentially the same as that reported by Cinacchi and Prampolini [4], that was obtained by the combination of B3LYP method and a 6-311G(2d, p) basis set. As shown in Fig. 2, there are two unique minima on the potential surfaces both in the $\mathrm{S}_{0}$ and $\mathrm{S}_{1}$ states. These two minima correspond to the trans $\left(\phi_{1}=0^{\circ}, \phi_{2}=180^{\circ}\right)$ and gauche $\left(\phi_{1} \approx 0^{\circ}, \phi_{2} \approx\right.$ $90^{\circ}$ ) forms and the former is the global minimum. At the both electronic states, the positions of the trans and gauche minima are different from each other essentially only in their $\phi_{2}$ values. Full geometry optimizations of the trans and gauche conformers were carried out for the $\mathrm{S}_{0}$ and $\mathrm{S}_{1}$ states. The obtained geometrical parameters are listed in Table 2. The resultant structural parameters show that the $\mathrm{S}_{0}-\mathrm{S}_{1}$ excitation makes the $\mathrm{C}-\mathrm{C}$ bonds in the ring longer by $0.01-0.04 \AA$ and $\mathrm{C}_{6}-\mathrm{C}_{1}-\mathrm{C}_{2}$ and $\mathrm{C}_{3}-\mathrm{C}_{4}-\mathrm{C}_{5}$ angles larger 
by about $4^{\circ}$. In going from the trans to gauche conformer, the $\mathrm{O}_{7}-\mathrm{C}_{8}-\mathrm{C}_{9}$ angle becomes larger by about $5^{\circ}$ and $3^{\circ}$ in the $S_{0}$ and $S_{1}$ states, respectively. At the both states, the $\phi_{2}$ angle of the gauche conformer is not around $60^{\circ}$, the typical value for the gauche, but close to $90^{\circ}$.

\subsection{Energy level analysis.}

The existence of the potential minimum does not mean the existence of the corresponding conformer unless there is at least one energy level with the probability distribution localized on the position of it. As shown in Fig. 2, the overall shape of the potential surfaces for the $S_{0}$ and $S_{1}$ states are quite different from each other. There is a strong coupling between the $\phi_{1}$ (ethoxy) and $\phi_{2}$ (ethyl) internal rotations in the $\mathrm{S}_{0}$ state. On the other hand, the coupling is much weaker in the $\mathrm{S}_{1}$ state. In the $\mathrm{S}_{0}$ state, the $\phi_{2}=$ $180^{\circ}$ cross section of the potential surface has its minima at $\phi_{1}=0^{\circ}$ and $180^{\circ}$. On the $\phi_{2}$ $=0^{\circ}$ cross section, however, the positions of the minima shifts to $\phi_{1}=90^{\circ}$ and $270^{\circ}$. Therefore, if the molecule carries out the ethyl internal rotation along with the minimum-energy path starting at $\left(\phi_{1}, \phi_{2}\right)=\left(+270^{\circ}, 0^{\circ}\right)$ toward $\phi_{2}=360^{\circ}$, the $\phi_{1}$ angle changes by $-180^{\circ}\left(\phi_{1}=+270^{\circ}\right.$ to $+90^{\circ}$, see the dashed line in Fig. 2$)$. That is, a half internal rotation of the ethoxy group takes place during a full internal rotation of the ethyl group. In such a case, it is not appropriate to treat the ethoxy and ethyl internal rotations separately by using a one-dimensional potential function for each. Therefore, the energy level calculations were carried out by means of the two-dimensional Hamiltonian [14],

$$
H=-\left(\begin{array}{ll}
\frac{\partial}{\partial \phi_{1}} & \frac{\partial}{\partial \phi_{2}}
\end{array}\right)\left(\begin{array}{ll}
B_{11} & B_{12} \\
B_{12} & B_{22}
\end{array}\right)\left(\begin{array}{c}
\frac{\partial}{\partial \phi_{1}} \\
\frac{\partial}{\partial \phi_{2}}
\end{array}\right)+V\left(\phi_{1}, \phi_{2}\right)
$$

where the elements, $B_{11}, B_{12}$ and $B_{22}$, in the kinetic energy term were approximated by the following expansion: 


$$
\begin{array}{r}
B_{i, j}\left(\phi_{1}, \phi_{2}\right)=\sum_{m, n=0}^{4} B_{i, j}^{\mathrm{c} \mathrm{m}, n} \cos \left(m \phi_{1}\right) \cos \left(n \phi_{2}\right)+\sum_{n=1}^{4} B_{i, j}^{\mathrm{s} 2, n} \sin \left(2 \phi_{1}\right) \sin \left(n \phi_{2}\right), \\
\quad(i, j=(1,1),(1,2),(2,2))
\end{array}
$$

The expansion coefficients, $B_{i, j}^{\mathrm{c} m, n}$ and $B_{i, j}^{\mathrm{s} 2, n}$, were functions of moment of inertia of the molecule and internal rotors, and they were evaluated by using a method similar to that described in Ref. [15].

The products of free rotation eigenfunctions, $\exp \left(\mathrm{i} k \phi_{1}\right) \exp \left(\mathrm{i} l \phi_{2}\right) / 2 \pi$, for $k, l=$ -40 to +40 were used as a basis set in order to calculate the energy levels and the corresponding wave functions by means of the matrix diagonalization. The probability distribution was calculated for each of the obtained energy levels by using their wave functions. Then the energy levels whose distribution is localized in the vicinity of the optimized $\phi_{1}$, and $\phi_{2}$ values for the gauche form (see Table 2) were assigned to that of the gauche conformer. Examples of the probability distribution for some of the energy levels for the $\mathrm{S}_{0}$ state are shown in Fig. 3.

For the $\mathrm{S}_{0}$ state, the lowest energy level assignable to the gauche conformer was found at $589 \mathrm{~cm}^{-1}$ higher than the lowest energy level of the trans conformer. On the other hand, the corresponding energy difference for the $\mathrm{S}_{1}$ state is $184 \mathrm{~cm}^{-1}$ (see Fig. 4). Therefore, it was expected that the $0-0$ band of the gauche conformer would be observed at $405 \mathrm{~cm}^{-1}$ red-shifted from that of the trans conformer.

\section{Results and discussions}

Figure 5 shows the observed fluorescence excitation spectrum of ethoxybenzene. The $0-0$ band of the trans conformer is observed at $36,375 \mathrm{~cm}^{-1}$, almost the same position as reported in Ref. [5]. The peak at $36,541 \mathrm{~cm}^{-1}\left(0-0\right.$ band $\left.+166 \mathrm{~cm}^{-1}\right)$ has been assigned in Ref. [5] to the vibronic fundamental band ( $\mathrm{C}-\mathrm{O}-\mathrm{C}$ in-plane bending) of the trans conformer on the basis of the dispersed fluorescence spectra and the theoretical calculation. At higher wavenumber range, many other vibronic bands can be observed, 
whose assignments are out of the scope of the present study. At the lower-wavenumber side of the $0-0$ band of the trans conformer, a very weak peak is found at $36,146 \mathrm{~cm}^{-1}$ $\left(-229 \mathrm{~cm}^{-1}\right.$ from the trans $0-0$ band). The position of this peak is out of the wavenumber range of the fluorescence excitation spectrum shown in Ref. [5]. As the intensity of this peak relative to the other peaks is almost unchanged even under a poor supersonic jet condition at which some hot band peaks appear, this peak does not seem to be a hot band of the trans conformer. No other peak was observed down to about $35,400 \mathrm{~cm}^{-1}$ under a cold jet condition. Therefore it is concluded that the peak at 36,146 $\mathrm{cm}^{-1}$ is the $0-0$ band of the second conformer (gauche) of ethoxybenzene. This conclusion (the existence of the gauche conformer) is qualitatively consistent with the present theoretical potential energy surface and with the result of the preliminary gas electron diffraction study reported previously [3]. As described in the Section 4, the $0-0$ band of the gauche conformer was supposed to be red-shifted by about $400 \mathrm{~cm}^{-1}$ from that of the trans conformer. However, the actual amount of the red-shift is found to be $229 \mathrm{~cm}^{-1}$. This discrepancy can be attributed to the limited accuracy of the theoretical potential surface, especially that for the $S_{1}$ state.

\section{Acknowledgements}

The authors thank the Research Center for Computational Science, Okazaki, Japan, for the use of the SGI Altix4700 computer and the Library Program Gaussian 09.

\section{References}

[1] D. Federsel, A. Herrmann, D. Christen, S. Sander, H. Willner, H. O. - L4, J. Mol. Struct., 567-568 (2001) 127.

[2] I. F. Shishkov, H. J. Geise, C. Van Alsenoy, L. V. Khristenko, L. V. Vilkov, V. M. Senyavian, B. Van der Veken, W. Herrebout, B. V. Lokshin, O. G. Garkusha, J. 
Mol. Struct., 567-568 (2001) 339.

[3] K. Kashiwagi, H. Takeuchi, T. Egawa, S. Konaka, Bunshi Kozo Sogo Toronkai, Higashihiroshima, Oct. 8-11, 1993, 1F02.

[4] G. Cinacchi, G. Prampolini, J. Phys. Chem. A, 107 (2003) 5228.

[5] V. Ramanathan, P. Pandey, T. Chakraborty, Chem. Phys. Lett., 427 (2006) 18.

[6] T. Egawa, T. Yamada, S. Konaka, Chem. Phys. Lett., 324 (2000) 260.

[7] Gaussian 09, Revision A.1, M. J. Frisch, G. W. Trucks, H. B. Schlegel, G. E. Scuseria, M. A. Robb, J. R. Cheeseman, G. Scalmani, V. Barone, B. Mennucci, G. A. Petersson, H. Nakatsuji, M. Caricato, X. Li, H. P. Hratchian, A. F. Izmaylov, J. Bloino, G. Zheng, J. L. Sonnenberg, M. Hada, M. Ehara, K. Toyota, R. Fukuda, J. Hasegawa, M. Ishida, T. Nakajima, Y. Honda, O. Kitao, H. Nakai, T. Vreven, J. Montgomery, J. A., J. E. Peralta, F. Ogliaro, M. Bearpark, J. J. Heyd, E. Brothers, K. N. Kudin, V. N. Staroverov, R. Kobayashi, J. Normand, K. Raghavachari, A. Rendell, J. C. Burant, S. S. Iyengar, J. Tomasi, M. Cossi, N. Rega, N. J. Millam, M. Klene, J. E. Knox, J. B. Cross, V. Bakken, C. Adamo, J. Jaramillo, R. Gomperts, R. E. Stratmann, O. Yazyev, A. J. Austin, R. Cammi, C. Pomelli, J. W. Ochterski, R. L. Martin, K. Morokuma, V. G. Zakrzewski, G. A. Voth, P. Salvador, J. J. Dannenberg, S. Dapprich, A. D. Daniels, Ö. Farkas, J. B. Foresman, J. V. Ortiz, J. Cioslowski, D. J. Fox, Gaussian, Inc., Wallingford CT, 2009.

[8] A. D. Becke, J. Chem. Phys., 98 (1993) 5648.

[9] C. Lee, W. Yang, R. G. Parr, Phys. Rev. B, 37 (1988) 785.

[10] T. H. Dunning Jr., J. Chem. Phys., 90 (1989) 1007.

[11] R. Bauernschmitt, R. Ahlrichs, Chem. Phys. Lett., 256 (1996) 454.

[12] M. E. Casida, C. Jamorski, K. C. Casida, D. R. Salahub, J. Chem. Phys., 108 (1998) 4439.

[13] R. E. Stratmann, G. E. Scuseria, M. J. Frisch, J. Chem. Phys., 109 (1998) 8218.

[14] T. Tsuji, H. Takashima, H. Takeuchi, T. Egawa, S. Konaka, J. Phys. Chem. A, 105 
(2001) 9347.

[15] M. A. Harthcock, J. Laane, J. Mol. Spectrosc., 91 (1982) 300. 
Table 1

Potential constants for the internal rotations of ethoxybenzene estimated by the least squares fitting on the potential energies obtained from the B3LYP/cc-pVTZ and TDDFT/B3LYP/cc-pVTZ calculations (in $\mathrm{cm}^{-1}$ )

\begin{tabular}{|c|c|c|}
\hline Param & & \\
\hline$V_{0,0}^{\mathrm{c}}$ & 1598.1 & 1931.9 \\
\hline$V_{0,1}^{\mathrm{c}}$ & 997.7 & 863.4 \\
\hline$V_{0,2}^{\mathrm{c}}$ & 362.1 & 346.9 \\
\hline$V_{0,3}^{\mathrm{c}}$ & 303.8 & 183.4 \\
\hline$V_{0,4}^{\mathrm{c}}$ & -52.7 & -36.9 \\
\hline$V_{0,5}^{\mathrm{c}}$ & -11.8 & -8.1 \\
\hline$V_{0,6}^{\mathrm{c}}$ & 2.7 & 0.8 \\
\hline$V_{2,0}^{\mathrm{c}}$ & -101.5 & -1216.0 \\
\hline$V_{2,1}^{\mathrm{c}}$ & 489.4 & 465.0 \\
\hline$V_{2,2}^{\mathrm{c}}$ & 254.9 & 254.2 \\
\hline$V_{2,3}^{\mathrm{c}}$ & 103.3 & -2.0 \\
\hline$V_{2,4}^{\mathrm{c}}$ & -80.2 & -61.2 \\
\hline$V_{2,5}^{\mathrm{c}}$ & -26.9 & -25.2 \\
\hline$V_{2,6}^{\mathrm{c}}$ & 3.7 & 2.4 \\
\hline$V_{4,0}^{\mathrm{c}}$ & 7.6 & 400.8 \\
\hline$V_{4,1}^{\mathrm{c}}$ & 25.3 & -26.1 \\
\hline$V_{4,2}^{\mathrm{c}}$ & 51.0 & 42.4 \\
\hline$V_{4,3}^{\mathrm{c}}$ & 114.2 & 73.4 \\
\hline$V_{4,4}^{\mathrm{c}}$ & -62.3 & -63.0 \\
\hline$V_{4,5}^{\mathrm{c}}$ & -24.0 & -29.2 \\
\hline$V_{4,6}^{\mathrm{c}}$ & 6.4 & 8.8 \\
\hline$V_{6,0}^{\mathrm{c}}$ & -4.3 & -86.6 \\
\hline$V_{6,1}^{\mathrm{c}}$ & -5.7 & 6.3 \\
\hline$V_{6,2}^{\mathrm{c}}$ & -5.6 & -2.6 \\
\hline
\end{tabular}




$\begin{array}{lrr}V_{6,3}^{\mathrm{c}} & 10.6 & 15.0 \\ V_{6,4}^{\mathrm{c}} & -10.6 & -20.2 \\ V^{\mathrm{c}}{ }_{6,5} & -5.6 & -12.4 \\ V^{\mathrm{c}}{ }_{6,6} & 2.5 & 1.7 \\ & & \\ V^{\mathrm{s}}{ }_{2,1} & -380.9 & -450.4 \\ V^{\mathrm{s}}{ }_{2,2} & -284.6 & -315.9 \\ V^{\mathrm{s}}{ }_{2,3} & -165.6 & -15.6 \\ V^{\mathrm{s}}{ }_{2,4} & 98.3 & 70.5 \\ V^{\mathrm{s}}{ }_{4,1} & -38.9 & 37.9 \\ V^{\mathrm{s}}{ }_{4,2} & -52.6 & -27.0 \\ V^{\mathrm{s}}{ }_{4,3} & -114.5 & -46.7 \\ V^{\mathrm{s}}{ }_{4,4} & 70.2 & 61.0\end{array}$

${ }^{\text {a }}$ See Eq. 1 for the definition of the potential constants. 
Table 2

Geometrical parameters and energies of trans and gauche conformers of ethoxybenzene obtained from the B3LYP/cc-pVTZ and TDDFT/B3LYP/cc-pVTZ calculations

\begin{tabular}{|c|c|c|c|c|}
\hline \multirow[b]{2}{*}{ Parameters $^{\mathrm{a}}$} & \multicolumn{2}{|c|}{$\mathrm{S}_{0}$ state (B3LYP/cc-pVTZ) } & \multicolumn{2}{|c|}{$\mathrm{S}_{1}$ state (TDDFT/B3LYP/cc-pVTZ) } \\
\hline & trans & gauche & trans & gauche \\
\hline \multicolumn{5}{|c|}{ Bond lengths / $\AA$} \\
\hline $\mathrm{C}_{1}-\mathrm{C}_{2}$ & 1.395 & 1.395 & 1.418 & 1.421 \\
\hline $\mathrm{C}_{2}-\mathrm{C}_{3}$ & 1.393 & 1.393 & 1.424 & 1.423 \\
\hline $\mathrm{C}_{3}-\mathrm{C}_{4}$ & 1.386 & 1.387 & 1.413 & 1.412 \\
\hline $\mathrm{C}_{4}-\mathrm{C}_{5}$ & 1.394 & 1.393 & 1.408 & 1.408 \\
\hline $\mathrm{C}_{5}-\mathrm{C}_{6}$ & 1.384 & 1.384 & 1.423 & 1.423 \\
\hline $\mathrm{C}_{6}-\mathrm{C}_{1}$ & 1.398 & 1.398 & 1.420 & 1.417 \\
\hline $\mathrm{C}_{1}-\mathrm{O}_{7}$ & 1.362 & 1.363 & 1.347 & 1.348 \\
\hline $\mathrm{O}_{7}-\mathrm{C}_{8}$ & 1.426 & 1.428 & 1.437 & 1.436 \\
\hline $\mathrm{C}_{8}-\mathrm{C}_{9}$ & 1.514 & 1.520 & 1.512 & 1.520 \\
\hline $\mathrm{C}_{2}-\mathrm{H}_{10}$ & 1.079 & 1.079 & 1.077 & 1.077 \\
\hline $\mathrm{C}_{3}-\mathrm{H}_{11}$ & 1.082 & 1.082 & 1.079 & 1.079 \\
\hline $\mathrm{C}_{4}-\mathrm{H}_{12}$ & 1.081 & 1.081 & 1.082 & 1.083 \\
\hline $\mathrm{C}_{5}-\mathrm{H}_{13}$ & 1.082 & 1.082 & 1.079 & 1.079 \\
\hline $\mathrm{C}_{6}-\mathrm{H}_{14}$ & 1.081 & 1.081 & 1.078 & 1.079 \\
\hline $\mathrm{C}_{8}-\mathrm{H}_{15}$ & 1.095 & 1.089 & 1.092 & 1.089 \\
\hline $\mathrm{C}_{8}-\mathrm{H}_{16}$ & 1.095 & 1.093 & 1.092 & 1.088 \\
\hline $\mathrm{C}_{9}-\mathrm{H}_{17}$ & 1.091 & 1.092 & 1.090 & 1.091 \\
\hline $\mathrm{C}_{9}-\mathrm{H}_{18}$ & 1.090 & 1.090 & 1.089 & 1.090 \\
\hline $\mathrm{C}_{9}-\mathrm{H}_{19}$ & 1.090 & 1.089 & 1.089 & 1.089 \\
\hline
\end{tabular}


Bond angles / ${ }^{\circ}$

\begin{tabular}{|c|c|c|c|c|}
\hline $\mathrm{C}_{6}-\mathrm{C}_{1}-\mathrm{C}_{2}$ & 119.6 & 119.4 & 123.1 & 123.1 \\
\hline $\mathrm{C}_{1}-\mathrm{C}_{2}-\mathrm{C}_{3}$ & 119.5 & 119.6 & 117.6 & 117.3 \\
\hline $\mathrm{C}_{2}-\mathrm{C}_{3}-\mathrm{C}_{4}$ & 121.0 & 121.0 & 119.5 & 119.8 \\
\hline $\mathrm{C}_{3}-\mathrm{C}_{4}-\mathrm{C}_{5}$ & 119.1 & 119.0 & 122.5 & 122.5 \\
\hline $\mathrm{C}_{4}-\mathrm{C}_{5}-\mathrm{C}_{6}$ & 120.6 & 120.6 & 118.9 & 118.6 \\
\hline $\mathrm{C}_{5}-\mathrm{C}_{6}-\mathrm{C}_{1}$ & 120.1 & 120.3 & 118.3 & 118.6 \\
\hline $\mathrm{C}_{2}-\mathrm{C}_{1}-\mathrm{O}_{7}$ & 124.5 & 125.2 & 122.9 & 123.3 \\
\hline $\mathrm{C}_{6}-\mathrm{C}_{1}-\mathrm{O}_{7}$ & 115.8 & 115.4 & 114.0 & 113.6 \\
\hline $\mathrm{C}_{1}-\mathrm{O}_{7}-\mathrm{C}_{8}$ & 119.1 & 120.4 & 121.4 & 122.2 \\
\hline $\mathrm{O}_{7}-\mathrm{C}_{8}-\mathrm{C}_{9}$ & 107.7 & 112.7 & 107.8 & 111.1 \\
\hline $\mathrm{C}_{1}-\mathrm{C}_{2}-\mathrm{H}_{10}$ & 121.0 & 121.1 & 121.4 & 121.8 \\
\hline $\mathrm{C}_{3}-\mathrm{C}_{2}-\mathrm{H}_{10}$ & 119.5 & 119.2 & 120.9 & 120.8 \\
\hline $\mathrm{C}_{2}-\mathrm{C}_{3}-\mathrm{H}_{11}$ & 119.0 & 118.9 & 120.3 & 120.1 \\
\hline $\mathrm{C}_{4}-\mathrm{C}_{3}-\mathrm{H}_{11}$ & 120.0 & 120.0 & 120.2 & 120.0 \\
\hline $\mathrm{C}_{3}-\mathrm{C}_{4}-\mathrm{H}_{12}$ & 120.4 & 120.5 & 118.6 & 118.6 \\
\hline $\mathrm{C}_{5}-\mathrm{C}_{4}-\mathrm{H}_{12}$ & 120.4 & 120.5 & 118.9 & 119.0 \\
\hline $\mathrm{C}_{4}-\mathrm{C}_{5}-\mathrm{H}_{13}$ & 120.0 & 120.1 & 120.4 & 120.6 \\
\hline $\mathrm{C}_{6}-\mathrm{C}_{5}-\mathrm{H}_{13}$ & 119.4 & 119.4 & 120.7 & 120.8 \\
\hline $\mathrm{C}_{5}-\mathrm{C}_{6}-\mathrm{H}_{14}$ & 121.4 & 121.3 & 122.9 & 122.8 \\
\hline $\mathrm{C}_{1}-\mathrm{C}_{6}-\mathrm{H}_{14}$ & 118.5 & 118.4 & 118.8 & 118.6 \\
\hline $\mathrm{O}_{7}-\mathrm{C}_{8}-\mathrm{H}_{15}$ & 109.8 & 104.3 & 108.7 & 104.1 \\
\hline $\mathrm{O}_{7}-\mathrm{C}_{8}-\mathrm{H}_{16}$ & 109.8 & 110.2 & 108.7 & 109.8 \\
\hline $\mathrm{C}_{9}-\mathrm{C}_{8}-\mathrm{H}_{15}$ & 110.8 & 110.2 & 111.6 & 110.7 \\
\hline $\mathrm{C}_{9}-\mathrm{C}_{8}-\mathrm{H}_{16}$ & 110.8 & 111.6 & 111.6 & 112.3 \\
\hline $\mathrm{H}_{15}-\mathrm{C}_{8}-\mathrm{H}_{16}$ & 107.9 & 107.4 & 108.4 & 108.6 \\
\hline $\mathrm{C}_{8}-\mathrm{C}_{9}-\mathrm{H}_{17}$ & 110.0 & 109.9 & 109.6 & 109.4 \\
\hline $\mathrm{C}_{8}-\mathrm{C}_{9}-\mathrm{H}_{18}$ & 110.7 & 110.3 & 110.9 & 110.7 \\
\hline $\mathrm{C}_{8}-\mathrm{C}_{9}-\mathrm{H}_{19}$ & 110.7 & 111.9 & 110.9 & 110.8 \\
\hline $\mathrm{H}_{17}-\mathrm{C}_{9}-\mathrm{H}_{18}$ & 108.5 & 108.3 & 108.4 & 108.4 \\
\hline $\mathrm{H}_{17}-\mathrm{C}_{9}-\mathrm{H}_{19}$ & 108.5 & 108.2 & 108.4 & 108.7 \\
\hline $\mathrm{H}_{18}-\mathrm{C}_{9}-\mathrm{H}_{19}$ & 108.4 & 108.2 & 108.5 & 108.7 \\
\hline
\end{tabular}


Dihedral angles / ${ }^{\circ}$

\begin{tabular}{|c|c|c|c|c|}
\hline $\mathrm{C}_{6}-\mathrm{C}_{1}-\mathrm{C}_{2}-\mathrm{C}_{3}$ & 0.0 & -0.3 & 0.0 & -1.3 \\
\hline $\mathrm{C}_{1}-\mathrm{C}_{2}-\mathrm{C}_{3}-\mathrm{C}_{4}$ & 0.0 & 0.2 & 0.0 & 2.7 \\
\hline $\mathrm{C}_{2}-\mathrm{C}_{3}-\mathrm{C}_{4}-\mathrm{C}_{5}$ & 0.0 & -0.0 & 0.0 & -1.3 \\
\hline $\mathrm{C}_{3}-\mathrm{C}_{4}-\mathrm{C}_{5}-\mathrm{C}_{6}$ & 0.0 & -0.1 & 0.0 & -1.5 \\
\hline $\mathrm{C}_{4}-\mathrm{C}_{5}-\mathrm{C}_{6}-\mathrm{C}_{1}$ & 0.0 & -0.0 & 0.0 & 2.8 \\
\hline $\mathrm{C}_{5}-\mathrm{C}_{6}-\mathrm{C}_{1}-\mathrm{C}_{2}$ & 0.0 & 0.2 & 0.0 & -1.4 \\
\hline $\mathrm{O}_{7}-\mathrm{C}_{1}-\mathrm{C}_{2}-\mathrm{C}_{3}$ & 180.0 & 179.0 & 180.0 & 178.5 \\
\hline $\mathrm{O}_{7}-\mathrm{C}_{1}-\mathrm{C}_{6}-\mathrm{C}_{5}$ & 180.0 & -179.1 & 180.0 & 178.7 \\
\hline $\mathrm{C}_{2}-\mathrm{C}_{1}-\mathrm{O}_{7}-\mathrm{C}_{8}\left(\phi_{1}\right)$ & 0.0 & 1.7 & 0.0 & -1.7 \\
\hline $\mathrm{C}_{6}-\mathrm{C}_{1}-\mathrm{O}_{7}-\mathrm{C}_{8}$ & 180.0 & -179.0 & 180.0 & 178.2 \\
\hline $\mathrm{C}_{1}-\mathrm{O}_{7}-\mathrm{C}_{8}-\mathrm{C}_{9}\left(\phi_{2}\right)$ & 180.0 & 82.2 & 180.0 & 90.8 \\
\hline $\mathrm{C}_{6}-\mathrm{C}_{1}-\mathrm{C}_{2}-\mathrm{H}_{10}$ & 180.0 & 179.5 & 180.0 & 174.1 \\
\hline $\mathrm{O}_{7}-\mathrm{C}_{1}-\mathrm{C}_{2}-\mathrm{H}_{10}$ & 0.0 & -1.2 & 0.0 & -6.0 \\
\hline $\mathrm{C}_{4}-\mathrm{C}_{3}-\mathrm{C}_{2}-\mathrm{H}_{10}$ & 180.0 & -179.6 & 180.0 & -172.8 \\
\hline $\mathrm{C}_{1}-\mathrm{C}_{2}-\mathrm{C}_{3}-\mathrm{H}_{11}$ & 180.0 & -180.0 & 180.0 & -178.8 \\
\hline $\mathrm{C}_{5}-\mathrm{C}_{4}-\mathrm{C}_{3}-\mathrm{H}_{11}$ & 180.0 & -179.8 & 180.0 & -179.8 \\
\hline $\mathrm{C}_{2}-\mathrm{C}_{3}-\mathrm{C}_{4}-\mathrm{H}_{12}$ & 180.0 & 179.9 & 180.0 & 178.7 \\
\hline $\mathrm{C}_{6}-\mathrm{C}_{5}-\mathrm{C}_{4}-\mathrm{H}_{12}$ & 180.0 & -180.0 & 180.0 & 178.5 \\
\hline $\mathrm{C}_{3}-\mathrm{C}_{4}-\mathrm{C}_{5}-\mathrm{H}_{13}$ & 180.0 & -180.0 & 180.0 & 179.7 \\
\hline $\mathrm{C}_{1}-\mathrm{C}_{6}-\mathrm{C}_{5}-\mathrm{H}_{13}$ & 180.0 & 179.9 & 180.0 & -178.4 \\
\hline $\mathrm{C}_{4}-\mathrm{C}_{5}-\mathrm{C}_{6}-\mathrm{H}_{14}$ & 180.0 & -179.8 & 180.0 & -174.6 \\
\hline $\mathrm{C}_{2}-\mathrm{C}_{1}-\mathrm{C}_{6}-\mathrm{H}_{14}$ & 180.0 & 180.0 & 180.0 & 176.2 \\
\hline $\mathrm{O}_{7}-\mathrm{C}_{1}-\mathrm{C}_{6}-\mathrm{H}_{14}$ & 0.0 & 0.6 & 0.0 & -3.7 \\
\hline $\mathrm{C}_{1}-\mathrm{O}_{7}-\mathrm{C}_{8}-\mathrm{H}_{15}$ & -59.2 & -158.2 & -58.9 & -150.0 \\
\hline $\mathrm{C}_{1}-\mathrm{O}_{7}-\mathrm{C}_{8}-\mathrm{H}_{16}$ & 59.2 & -43.2 & 58.9 & -34.0 \\
\hline $\mathrm{O}_{7}-\mathrm{C}_{8}-\mathrm{C}_{9}-\mathrm{H}_{17}$ & 180.0 & 176.3 & 180.0 & 176.1 \\
\hline $\mathrm{O}_{7}-\mathrm{C}_{8}-\mathrm{C}_{9}-\mathrm{H}_{18}$ & 60.1 & 56.9 & 60.3 & 56.6 \\
\hline $\mathrm{O}_{7}-\mathrm{C}_{8}-\mathrm{C}_{9}-\mathrm{H}_{19}$ & -60.1 & -63.5 & -60.3 & -64.1 \\
\hline
\end{tabular}


$E / E_{\mathrm{h}}$

$-386.23274$

$-386.23008$

$-386.05175$

$-386.05083$

$\Delta E^{\mathrm{b}} / \mathrm{cm}^{-1}$

0.0

583.2

0.0

204.2

${ }^{a}$ See Fig. 1 for the atom numbering.

${ }^{\mathrm{b}} \Delta E=E($ gauche $)-E$ (trans). 


\section{Figure captions}

Fig. 1 Molecular models and atom numberings of the trans and gauche conformers of ethoxybenzene. The internal rotation angles, $\phi_{1}$ and $\phi_{2}$, are defined as $\phi_{1}=$ $\phi\left(\mathrm{C}_{2}-\mathrm{C}_{1}-\mathrm{O}_{7}-\mathrm{C}_{8}\right)$ and $\phi_{2}=\phi\left(\mathrm{C}_{1}-\mathrm{O}_{7}-\mathrm{C}_{8}-\mathrm{C}_{9}\right)$.

Fig. 2 Potential surfaces for the $\mathrm{S}_{0}$ and $\mathrm{S}_{1}$ states of ethoxybenzene obtained from the B3LYP/cc-pVTZ $\left(\mathrm{S}_{0}\right)$ and TDDFT/B3LYP/cc-pVTZ $\left(\mathrm{S}_{1}\right)$ calculations. See Fig. 1 for the definitions of $\phi_{1}$ and $\phi_{2}$. The contour interval is $200 \mathrm{~cm}^{-1}$. The dashed lines on the $\mathrm{S}_{0}$ potential surface are the minimum-energy paths for the $\phi_{2}$ (ethyl) internal rotation.

Fig. 3 Some examples of the contour plot of the probability distribution for the $\phi_{1}$ (ethoxy) and $\phi_{2}$ (ethyl) internal rotations of ethoxybenzene for the $\mathrm{S}_{0}$ state. See Fig. 1 for the definitions of $\phi_{1}$ and $\phi_{2}$. Energy value for each level measured from the global potential minimum as well as the assignment for the conformer and the vibrational quantum number is shown.

Fig. 4 Vibrational energy levels for the $\phi_{1}$ (ethoxy) and $\phi_{2}$ (ethyl) internal rotations of ethoxybenzene for the $\mathrm{S}_{0}$ and $\mathrm{S}_{1}$ states.

Fig. $5 \quad \mathrm{~S}_{1} \leftarrow \mathrm{S}_{0}$ fluorescence excitation spectrum of jet-cooled ethoxybenzene. The upper scale shows the excess energy measured from the $0-0$ band of the trans conformer appearing at $36375 \mathrm{~cm}^{-1}$. 
Figure 1
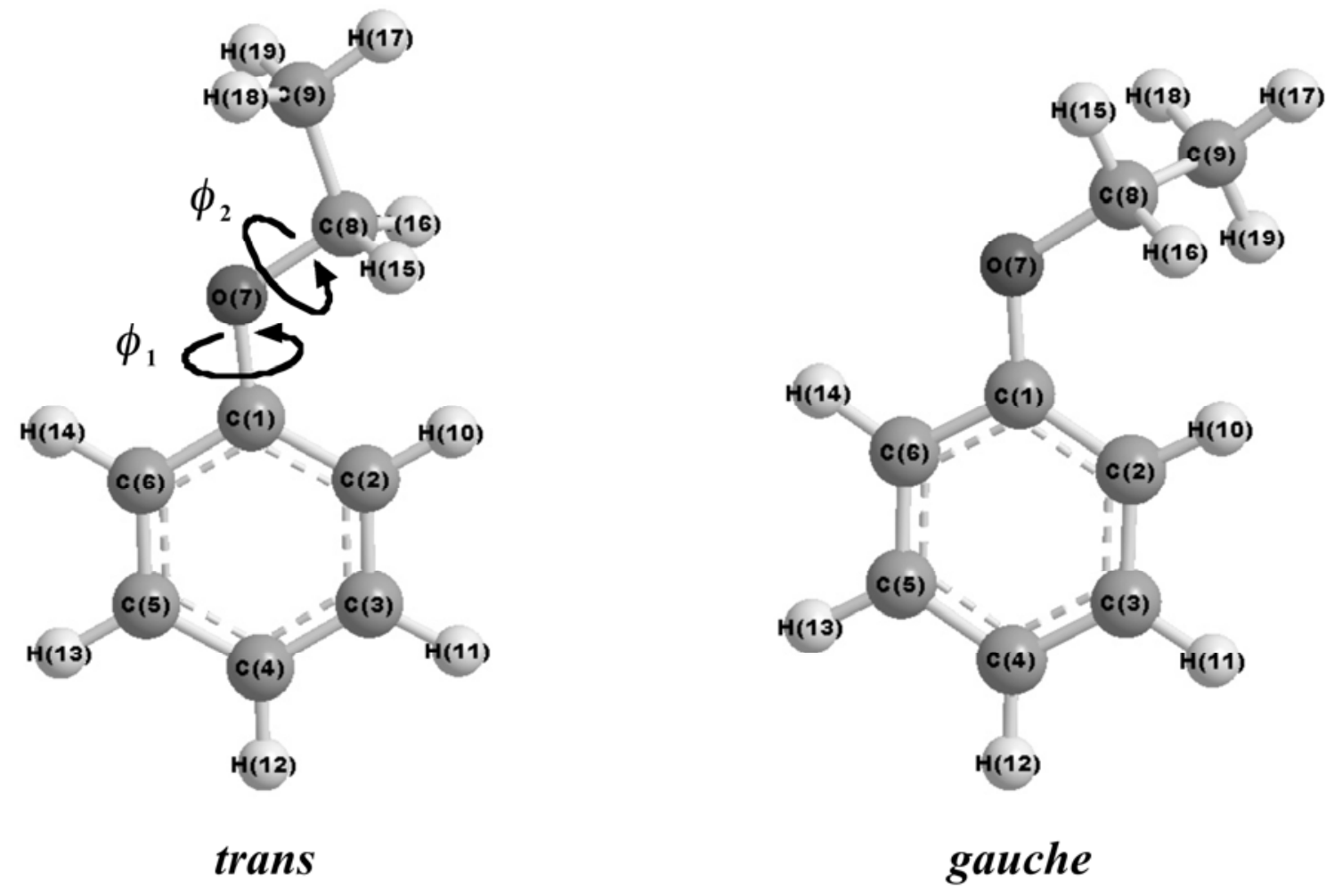
Figure 2

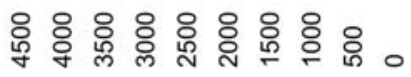
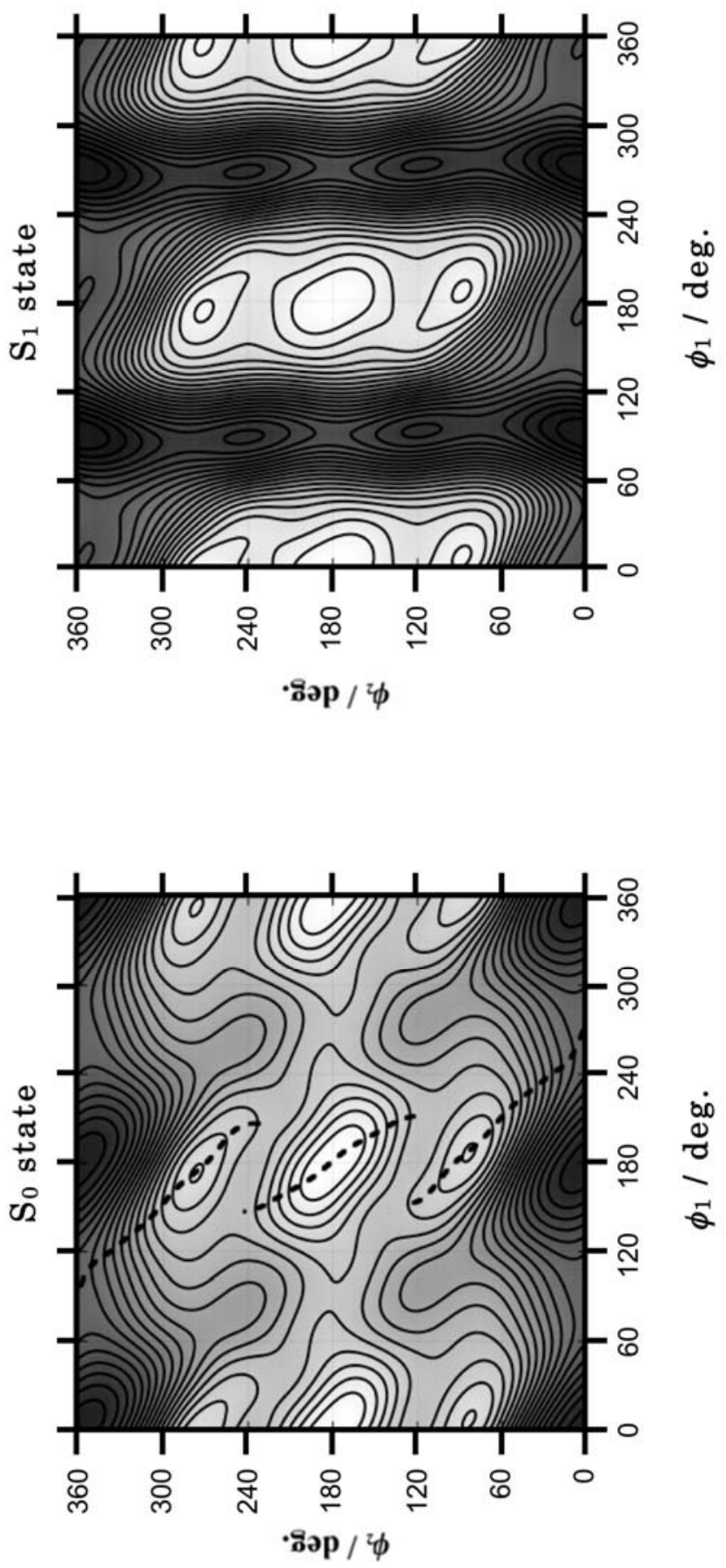
Figure 3

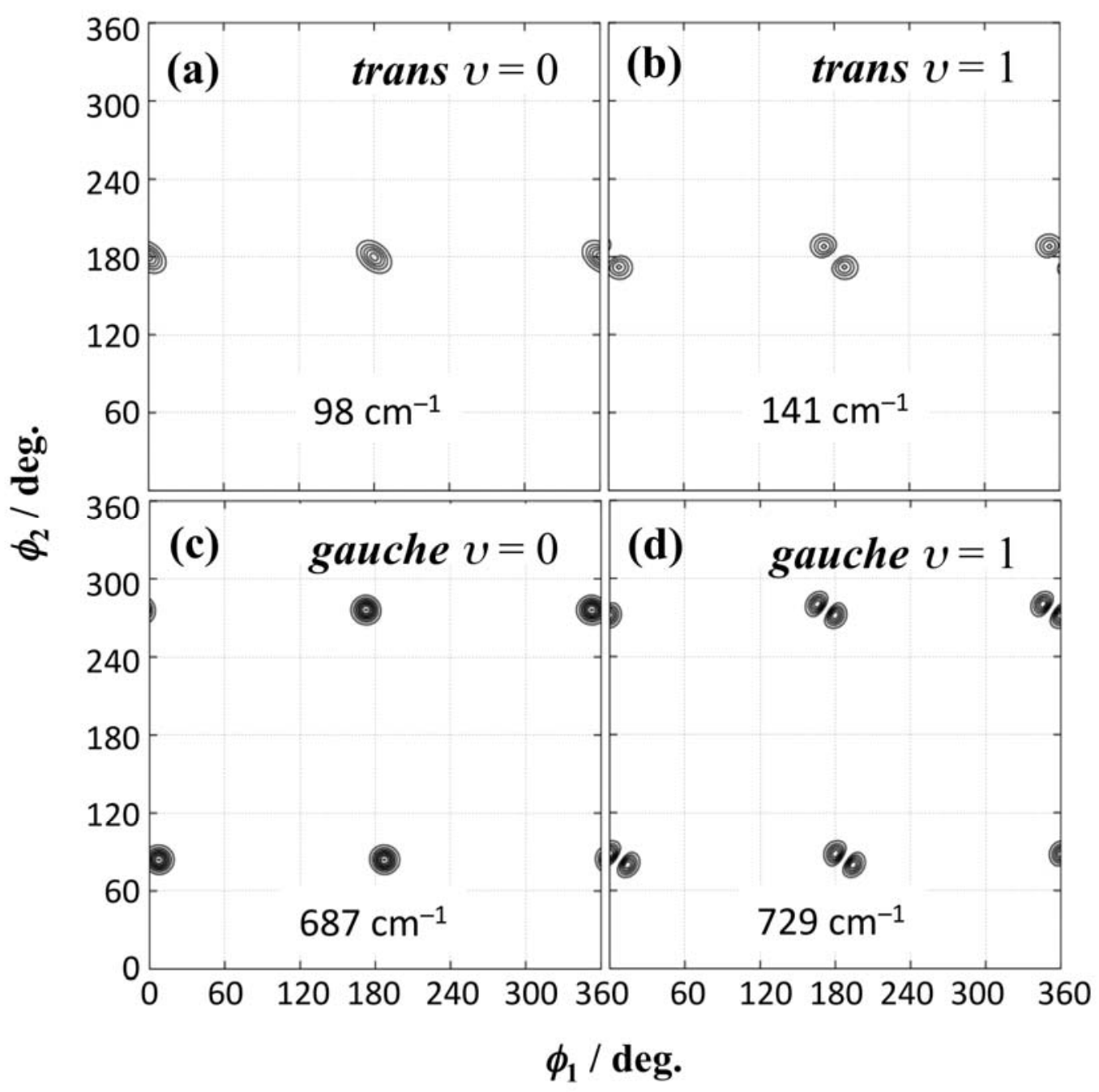


Figure 4
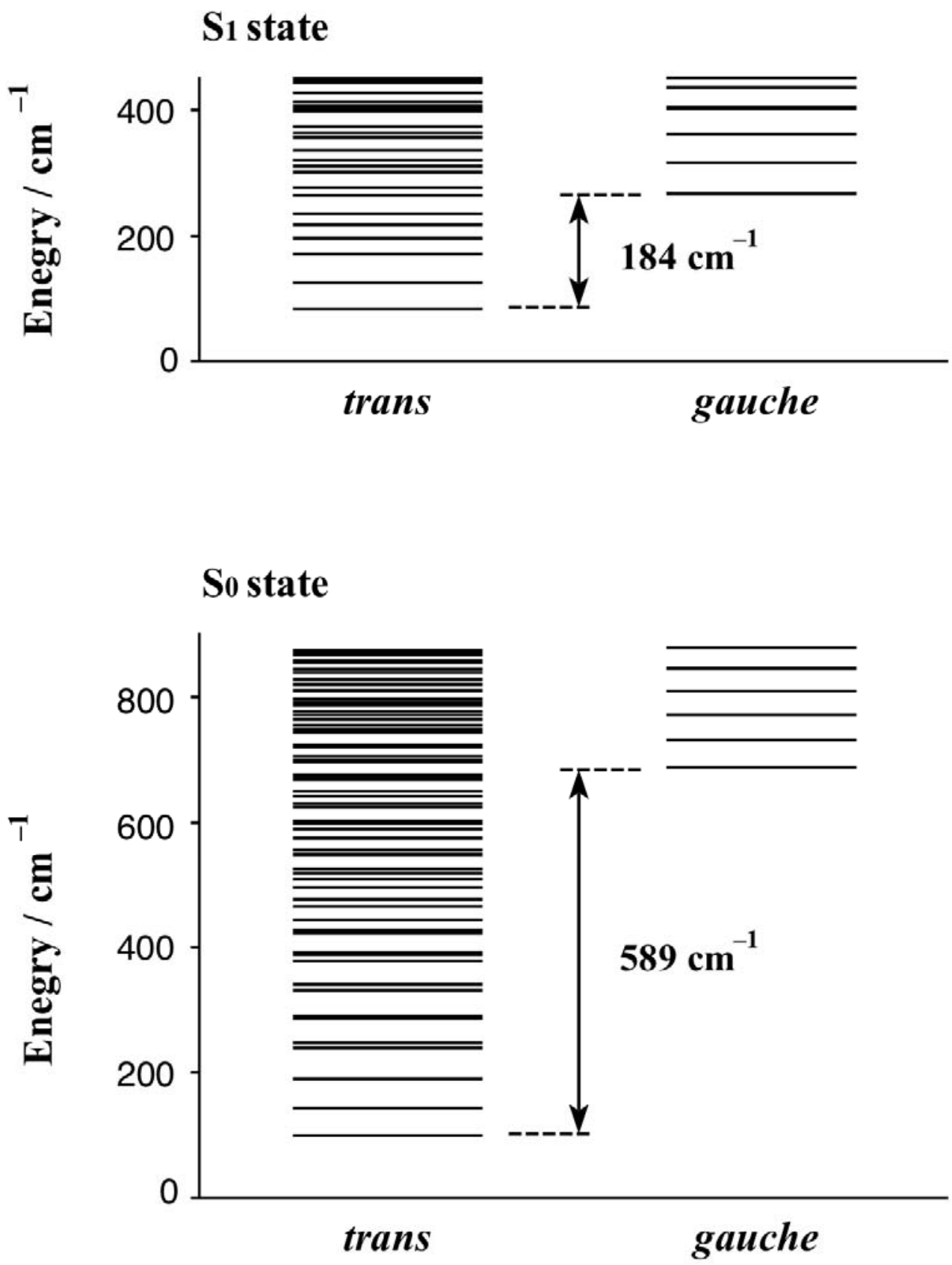
Figure 5

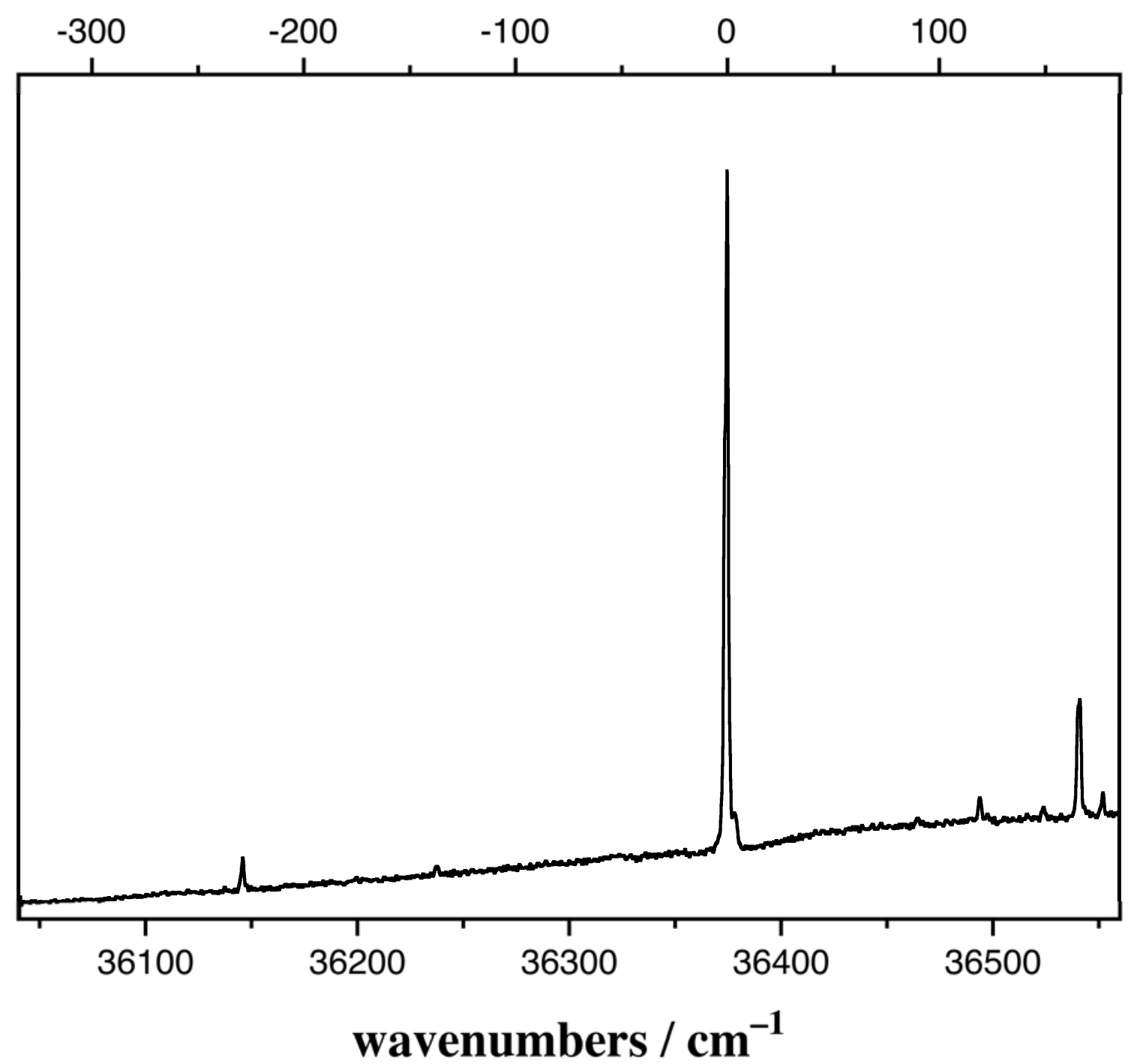

